\section{Pacific Northwest}

National Laboratory

Operated by Battelle for the

US. Department of Energy

\title{
Recommendations for Glass Durability Test Criteria
}

D. M. Strachan

December 1998

$$
\begin{array}{r}
\text { RECEIVED } \\
\text { FEB } 17 \text { 1999 } \\
\text { OSTI }
\end{array}
$$

Prepared for the U.S. Department of Energy under Contract DE-AC06-76RLO 1830 


\title{
DISCLAIMER
}

This report was prepared as an account of work sponsored by an agency of the United States Government. Neither the United States Government nor any agency thereof, nor Battelle Memorial Institute, nor any of their employees, makes any warranty, express or implied, or assumes any legal liability or responsibility for the accuracy, completeness, or usefulness of any information, apparatus, product, or process disclosed, or represents that its use would not infringe privately owned rights. Reference herein to any specific commercial product, process, or service by trade name, trademark, manufacturer, or otherwise does not necessarily constitute or imply its endorsement, recommendation, or favoring by the United States Government or any agency thereof, or Battelle Memorial Institute. The views and opinions of authors expressed herein do not necessarily state or reflect those of the United States Government or any agency thereof.

\author{
PACIFIC NORTHWEST NATIONAL LABORATORY \\ operated by \\ BATTELLE \\ for the \\ UNITED STATES DEPARTMENT OF ENERGY \\ under Contract DE-AC06-76RLO 1830
}

Printed in the United States of America

Available to DOE and DOE contractors from the

Office of Scientific and Technical Information, P.O. Box 62, Oak Ridge, TN 37831;

prices available from (615) $576-8401$.

Available to the public from the National Technical Information Service, U.S. Department of Commerce, 5285 Port Royal Rd, Springfield, VA 22161

This document was printed on recycled paper: 


\section{DISCLAIMER}

This report was prepared as an account of work sponsored by an agency of the United States Government. Neither the United States Government nor any agency thereof, nor any of their employees, make any warranty, express or implied, or assumes any legal liability or responsibility for the accuracy, completeness, or usefulness of any information, apparatus, product, or process disclosed, or represents that its use would not infringe privately owned rights. Reference herein to any specific commercial product, process, or service by trade name, trademark, manufacturer, or otherwise does not necessarily constitute or imply its endorsement, recommendation, or favoring by the United States Government or any agency thereof. The views and opinions of authors expressed herein do not necessarily state or reflect those of the United States Government or any agency thereof. 


\section{DISCLAIMER}

Portions of this document may be illegible in electronic image products. Images are produced from the best available original document. 


\section{Introduction}

To dispose waste from the Hanford high-level waste tanks, the waste will be treated to separate it into high-activity and a low activity-waste streams. Each of these streams will be converted to a less mobile form. In the case of the low-activity waste stream, the product will be a glass, the composition of which remains to be defined. Much of the process of treating and converting the waste, including the composition of the glass to be produced, will be the responsibility of a private vendor. The chemical and physical properties of the glass must meet certain criteria that are to be specified in a contract between the vendor and the Department of Energy. One of these criteria, the chemical durability, must be defined so that the vendor has a quantifiable specification and the Department of Energy has a material that will meet the needs the disposal requirements. The specification for the vendor must be embodied in a test from which a certain result is obtained for the glass(es) that is produced. For the Department, the challenge is defining a specification that can be used as an indicator of long-term behavior of that glass in contact with water.

My emphasis here is on the behavior of the glass as a waste form. It is well recognized that, as the glass dissolves, alteration products are formed. The identification and chemical behavior of these alteration phases is important because many of them incorporate radionuclides from the glass. While these alteration products are important from a radionuclide-release point of view, they, like the glass from which they are formed, do not necessarily represent phases with longevity. As solution composition and disposal site conditions change, these phases may become unstable with respect to other alteration phases. Some of these changes can be calculated as part of the system performance assessment. However, a more conservative approach is to rely upon the behavior of the glass waste form (the source term) to meet the expectations of the regulators and stakeholders. Any credit that can be taken for the alteration products, therefore, leads to added assurance that the waste can be safely stored. In this paper, I focus on the glass as the source term and only consider alteration products when they have an impact on the behavior of the glass.

The objective, therefore, of this short report is to define a set of activities that should lead to a specification for a test that can be used as one of the acceptance criteria and as an indicator of acceptable longterm behavior in contact with water. Since the glass composition is not yet defined and is likely to change as the composition of the waste changes, a strategy for developing criteria for what is acceptable involves a series of tests and modeling activities. The results of these activities lead to a criterion for an acceptable product and the data that are needed to reliably determine the behavior of the glass in the storage environment.

\section{Background}

Evaluating the behavior of glass in contact with water over periods of thousands of years is needed to assure the regulators and stakeholders that nuclear waste glass can be safely disposed. This is the case 
whether the glass contains low-activity or high-level waste. The performance period for the low-activity waste glass is 100000 years. An assessment of glass corrosion over these time scales can only be made if the environmental conditions are known and the behavior of a glass waste form and the glass alteration products are either known or can be calculated (modeled). It is, therefore, unlikely that this assurance can be obtained through extrapolation of laboratory results nor through a prediction ${ }^{(a)}$ of repository or disposal site conditions based on past geological events. What will be required is an understanding of the behavior of the glass in contact with water under a variety of conditions so that credible releases of radionuclides can be calculated through a performance assessment activity for a range of anticipated geologic events/conditions.

To accomplish this task, it must be possible to calculate the behavior of glass in contact with water. Fortunately, there exists a well-accepted model for the dissolution rate of glass that incorporates many of the known parameters that affect glass dissolution (Eqn.1) (McGrail and Peeler 1995).

$$
\mathrm{k}=\mathrm{k}_{0} 10^{\eta \cdot \mathrm{pH}} \mathrm{e} \frac{-\mathrm{E}_{\mathrm{a}}}{\mathrm{RT}}\left(1-\frac{\mathrm{Q}}{\mathrm{K}}\right)
$$

This rate equation is a mathematical description of the rate of dissolution for the glass matrix where $k_{0}$ is the intrinsic dissolution rate that depends on composition, $\eta$ is the coefficient for the dependence on $\mathrm{pH}$, $\mathrm{E}_{\mathrm{a}}$ is the activation energy, $\mathrm{Q}$ is the ion activity product for the species involved in the rate-limiting step, and $\mathrm{K}$ is the equilibrium constant for the rate-limiting reaction. Equation 1 is not, however, a complete description of the chemical and physical system for the glass. For example, the rate at which alteration products form as the glass dissolves is not described in the mathematical formulation shown in Equation 1. This is not a significant deficiency, since all other processes that are likely to affect the dissolution rate are assumed, for calculation purposes, to occur rapidly. Another important process that is not included in Eqn. 1 is the ion exchange that takes place when glass first comes in contact with water. This may be a serious deficiency since the corrosion behavior of at least one candidate low activity waste glass, LD65412 , appears to be dominated by the ion exchange process in some tests and test conditions for periods on the order of a year.

What is generally accepted about Eqn. 1 is that it is a description of the rate limiting step in the overall description of the chemical system (Strachan, McGrail, and Bourcier 1993). The rate-limiting step is the slowest reaction in a sequence of chemical reactions starting with the glass plus water and ending with dissolved glass and alteration products. Experimental values for the parameters $k_{0}, E_{a}, \eta$, and $K$ appear to be insensitive to glass composition, implying that the rate limiting step is the same for all silica-based glasses. "Insensitive" refers to the variation across a wide variety of glasses being less than a factor of ten and, perhaps, less than a factor of three. This means that if we are to find a discriminator for the longterm behavior of various glasses in contact with water, we must look to the remaining term, $Q$, and modeling to provide the assurance that is needed to dispose of nuclear waste.

(a) Here "prediction" is used in the true sense of an a prioi forecasting of how the chemical and physical conditions at the disposal site will evolve with time. 
Although there is some indication that the rate law may be more complex and include the effects of catalytic/inhibitory chemical species, there are insufficient data to support a change from the accepted position that value of $\mathrm{Q}$ is the solution concentration of orthosilicic acid, $\left[\mathrm{H}_{4} \mathrm{SiO}_{4}\right]$. Effects on the dissolution rate of glass are, therefore, manifest through the impacts that environmental conditions have on the concentration of $\mathrm{H}_{4} \mathrm{SiO}_{4}$. Although environmental conditions such as temperature also affect the dissolution rate directly through the other parameters such as the exponential term in Eqn. 1, there is an indirect effect through the temperature dependence of the ionization constant for $\mathrm{H}_{4} \mathrm{SiO}_{4}$. The most significant impact on the concentration of $\mathrm{H}_{4} \mathrm{SiO}_{4}$ comes when alteration phases form that cause a pronounced decrease in the $\left[\mathrm{H}_{4} \mathrm{SiO}_{4}\right]^{(\mathrm{a})}$ As a class, zeolites have been found to cause glass dissolution rates to increase even after long times at low dissolution rates. The formation of zeolites after long times has been observed to affect the dissolution of some glasses (Bakel, Ebert, and Luo 1995; Gong et al. 1998), under static conditions. The effect of zeolite precipitation is shown schematically in Figure 1. Strachan and Croak (1998) have suggested that the formation of zeolites under static conditions and the subsequent effect on the dissolution rate be correlated to the glass composition.

Returning to Eqn. 1, it can be said that so long as rate law is valid, the effects of environmental conditions on the dissolution rate can be calculated. From the above discussion, we know that so long as the release of radionuclides is through the interaction of glass with water, the release rate of these radionuclides from the glass can be calculated under all credible scenarios for the disposal or repository site. Therefore, if the flow of water changes, the release rate can be calculated such that the change in release of radionuclides can be calculated. Changes to the water composition when incoming ground water

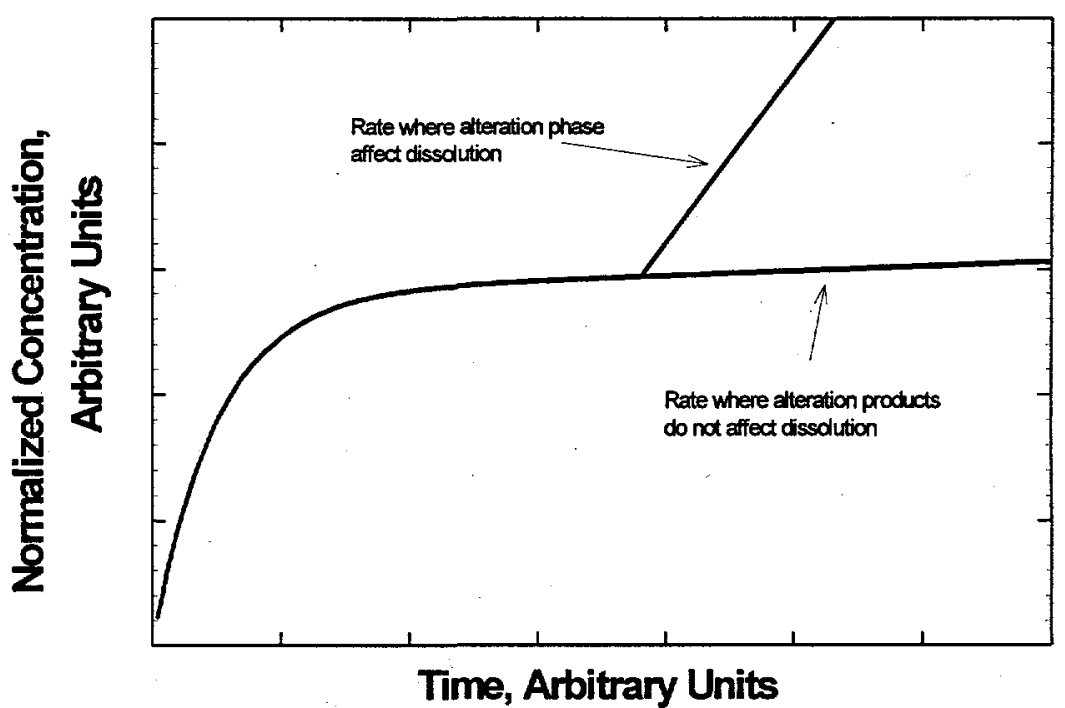

Figure 1. Generic Glass Dissolution Showing How Alteration Phases Can Affect the Glass Dissolution Rate

(a) This refers to the chemical species $\mathrm{H}_{4} \mathrm{SiO}_{4}$. The total $\mathrm{Si}$ in the solution may go up because of other changes to the solution as a result of rapid glass dissolution. For example, the $\mathrm{pH}$ usually increases. At the higher $\mathrm{pH}$ values, the $\left[\mathrm{H}_{4} \mathrm{SiO}_{4}\right]$ may decrease while the total $\mathrm{Si}$ in solution increases. 
interacts with barrier materials, such as concrete, also affect the dissolution rate of the glass. These can be calculated either because they have a direct (one of the parameters) or indirect (Q) effect in Eqn. 1. Some of the released (from the glass) radionuclides may also become part of the precipitated alteration products, either in solid solution or as separate phases. It is important, therefore, that both the experimental and modeling efforts result in a data base that can be used for model validation and in a model that accurately reflects the long-term behavior of glass in contact with water (McGrail et al. 1998). The fates of the radionuclides that have been released from the glass also need to be tracked. While these may become part of the suite of alteration products, the behavior of these alteration products as a function of time (changes in solution/conditions) must also be calculated or verified experimentally.

\section{An Approach to a Solution}

As indicated above, the problem that needs to be addressed is the acceptance of a glass product of some composition to fill the performance needs of a disposal site. More is known about the disposal site than is known about the glass that will ultimately be stored there. Although there should be a database on the testing by the vendor, the acceptance will be based on the results from an acceptance test. As currently formulated, this test is a product consistency test (PCT-A, ASTM 1994). The results from this test have not been shown to be a good indicator of the long-term behavior of the glass in contact with water. Since it is the responsibility of the Department of Energy to dispose of this glass and to show that it meets the expectations for performance, the Department must show the connection between the acceptance criteria and the long-term behavior. The methodology to accomplish this task is provided in the ASTM 1174 (ASTM 1992) approach to the determination of the long-term dissolution of the glass. Because this is a consensus standard, it represents the best-discussed and viable approach. In the standard guide, the essence of the approach is one of testing and modeling. What is somewhat different between the basis of the ASTM standard guide and the problem at hand is the need to accept a glass of some composition and know that this glass has the dissolution properties that fill the performance needs as determined in the performance assessment (Mann et al. 1998). So, instead of determining the long-term behavior of a single glass, there is a need to show that the target glass composition and variations about the target have an acceptable long-term behavior. It must also be shown that the results from a PCT-A or some other test are sensitive to the changes in composition and that a reliable connection can be provided between that result and the long-term behavior.

There are three approaches to showing the connection between the results from a short-term acceptance test and acceptable long-term behavior. In the first approach, rigorous testing of glass compositions that bracket the target composition of the glass that is to be produced for a given waste or class of wastes. Test duration's would vary from very short to very long, probably much longer than the time available. Results from tests performed under conditions that are known to accelerate the dissolution would also be needed. This is a purely experimental approach that is inconsistent with the ASTM 1174 basis and, hence, not recommended.

In the second approach, tests are performed that show the validity of a pure modeling approach where glass compositions are either shown to not form zeolites under any case or if zeolites form, there is no 
effect on the dissolution rate or the effect is minimal. The strategy is to determine the effect of alteration phase formation, not to calculate the evolution of the solution concentrations. This approach is, as yet, untested and would involve the testing of both the target glass compositions and a set of surrogate glasses (see below). This approach is more risky than the first in that it is currently just proposed (Strachan and Croak 1998). However, once it has been shown to be valid, the payback is high because a pure modeling approach could be taken with only a minimal amount of additional testing. This would allow the Department to make quick decisions on changes in product composition and run a directed number of tests to validate the model results.

A third and perhaps more viable approach, given the time that results are needed, is a combination of the first two approaches. In either case, extensive testing is needed. Tests are needed on the target glass composition and on glass compositions that represent processing variations or waste variations. Modeling of these glasses can be performed to determine the effect of zeolite formation and to calculate the evolution of the solution concentrations. These modeling results can then be compared with the results from the tests for both zeolite formation and solution evolution. In this case, the modeling becomes more complicated than the modeling in the second approach discussed briefly above because the glass compositions involve more components. Therefore, the solution concentrations are subject to the uncertainties involved in selecting the alteration products that are allowed to precipitate in the simulation and on the uncertain thermodynamics for some of these phases. However, this might be the best chance to develop a data base from both testing and modeling that can be used to establish the acceptance criteria and the connection between the criterion and the long-term behavior. This approach is also consistent with the intent of ASTM 1174.

In any event, to accept a glass, an extensive database is needed to establish the long-term behavior and the results from a single test or a series of very short and simple tests are needed for the vendor. The results from these tests must be accurate indicators of the long-term quality of the glass to be accepted. Placing an "acceptance" value on the results from a single or multiple tests means that there exists a connection between the test result and the long-term behavior of the glass under disposal or repository site conditions. The impossibility of doing this a priori is illustrated in Figure 2. If, for example, a PCT-A (ASTM 1994) result is required to be a certain value for the glass to be accepted, then the number of curves (glass behavior) that can be drawn through the point that represents the acceptable value are not only infinite, but also span the range from acceptable to unacceptable long-term behavior. In addition, since the PCT-A is performed with demineralized water, the effect of water that has first contacted a cement barrier can not be determined. Both of these illustrations show the impossibility of projecting the result from a single test to the long-term behavior of a glass or to the behavior in contact with fluids a the repository or disposal site without some way of putting the results from the testing into context.

This seemingly hopeless situation can be resolved with extensive testing and modeling. By testing glass compositions that bracket the glass compositions that are to be produced, the test matrix can be limited and constrains the composition space over which the modeling is valid. For example, if the target glass is to be six component glasses the composition of which is expected to vary at most by $\pm 10 \%$ in each of the six components, then a test matrix consisting of glass compositions that span that composition space must be developed and the glasses tested. Dissolution tests consisting of PCT-A, PCT-B, vapor hydration test (VHT, Bates and Steindler 1983), and/or flow conditions (single-pass flow-through or 


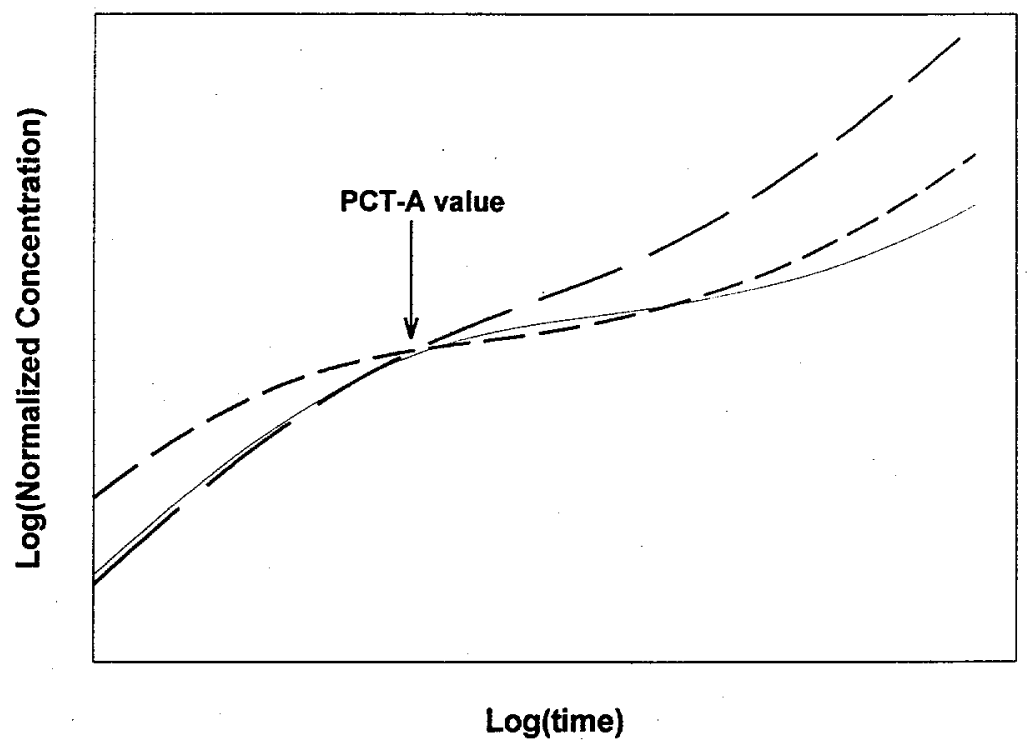

Figure 2. Generic Glass Dissolution Behavior Illustrating the Difficulty With Promulgating a PCT-A Criterion for Glass Behavior

pressurized unsaturated flow tests) need to be performed on a statistical number of the glasses in this composition space. This yields a database for model validation. The goal of this testing program would not be to obtain a statistical extrapolation model, but a database for model validation. Statistical compositional variation approaches, such as those used to develop glasses (Chick et al. 1986; Hrma et al. 1992), are of little use to performance assessment calculations because they are blind to the complex chemistry involved and are statistically-based extrapolations of experimental data.

Glass dissolution modeling should be carried out on a number of the glasses within the composition matrix. A comparison of the calculated solution compositions and the experimentally observed solution compositions should be done. These comparisons should lead to confidence in the ability to model the glass reaction. Results from the tests will yield values for the parameters in Eqn. 1 that can be used in the model to calculate the solution composition as a function of time. As part of the model output, the existence of zeolites should be known as should the effect that these zeolites have on the rate of glass dissolution. This too should be compared with the results of testing. These results could then be used to develop a set of graphs, such as those presented by Strachan and Croak (1998) to show the effect of composition on the long-term interaction of glass with water. This effort produces a series of graphs, such as shown in Figure 3 that can be used to determine if a glass is likely to have good or poor long-term behavior. The surface that appears in Figure 3 represents the upper stability of these glasses. Therefore, those glasses with compositions that plot in the area where the surface appears at low reaction progress are glasses that are projected to have poor long-term behavior. These theoretically generated plots would be validated against the results from the experiments and modeling activities. This, plus the model validation with respect to solution concentrations, would yield a complete package that allows a dissolution specification to be promulgated as a result from a single test and a source-term model to be used in performance assessment calculations. 


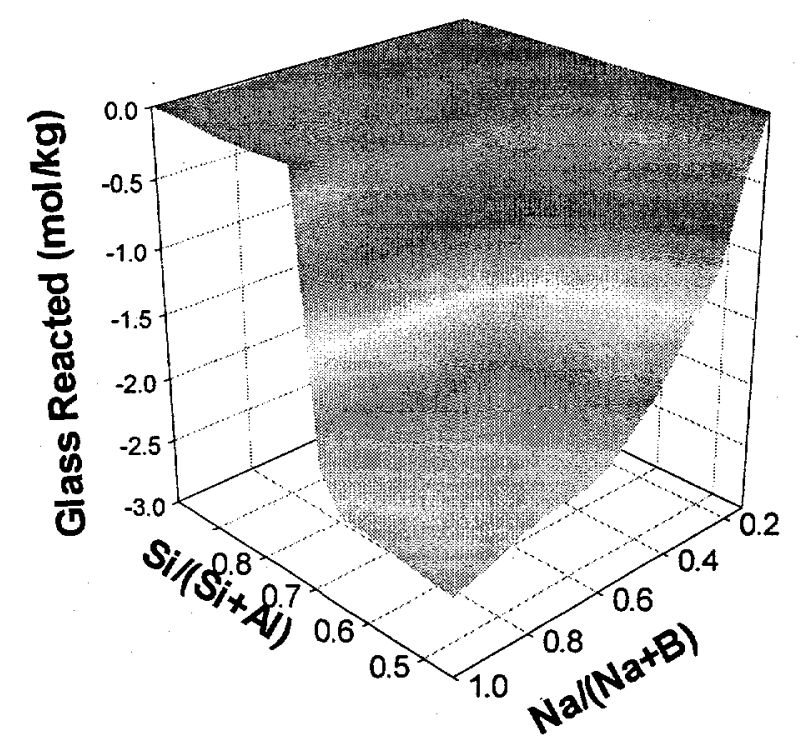

Figure 3. An Illustration of the Effect of Composition on Glass "Stability"

\section{Recommendation}

A series of tests on a range of vendor compositions is needed. However, to show that these results are indicators of the long-term behavior in contact with water, modeling must also be carried out and validated against the results from specific experiments. Experimentally, there are relatively simple tests that can be used as indicators of long-term behavior and should be used on all glasses in the experimental set. There are some more complex tests such as the PUF (McGrail, Martin, and Lindenmeier 1997) that must also be performed, but on a limited set of glasses within the larger set. The tests that should be performed on all glasses in the set are the VHT at $150^{\circ} \mathrm{C}$ and the PCT-B at $20000 \mathrm{~m}^{-1}$ and $90^{\circ} \mathrm{C}$. The results from the VHT can be obtained in $14 \mathrm{~d}$ since that is how long it took for alteration phases to affect the dissolution of LD6-5412 glass and performance assessment calculations showed that LD6-5412 had acceptable long-term behavior. Likewise, the results from the other glasses should be compared to the results from the LD6-5412 glass as an indicator of the maximum acceptable rate.

Results from the "screening" tests described above should allow the larger matrix to be reduced to a smaller set and a narrower range of compositions. These glasses should be tested more extensively with the same test methods, but for longer periods of time and over a wider range of conditions.

Additionally, there needs to be sufficient testing with the PCT-A to show that this can or can not be used as a product control for acceptable products. These tests should be performed on a selected number of glasses within the reduced set of glasses and a few glasses that are just outside the bounds of the established set. Within the set of glasses, there should be a core of glasses that are found to have the best behavior. These glasses should be tested much more extensively (all tests) and for much longer periods 
of time (one year or more). Modeling calculations need to be performed on these core glasses plus additional glasses to show the effect of zeolites, to calculate the evolution of solution composition, and to provide information on the effect of glass composition on the long-term dissolution of glass. These results should provide confidence in the establishment of an acceptance specification for the vendor glasses that is based on a simple, short-term test and provide better confidence in source-term for the performance assessment calculations.

\section{References}

American Society for Testing and Materials. 1991. Standard Practice for Prediction of the Long-Term Behavior of Waste Package Materials Including Waste Forms Used in the Geologic Disposal of HighLevel Nuclear Waste, ASTM C 1174-91, American Society for Testing and Materials, Philadelphia, Pennsylvania.

American Society for Testing and Materials. 1994. Standard Test Method for Determining the Chemical Durability of Nuclear Waste Glasses: The Product Consistency Test (PCT), ASTM C 1285-94, American Society for Testing and Materials, Philadelphia, Pennsylvania.

Bakel, A. J., W. L. Ebert, and J. S. Luo. 1995. "Long-Term Performance of Glasses for Hanford LowLevel Waste," Ceramic Transactions Environmental and Waste Management Issues in the Ceramic Industry, 61, 515-522.

Bates, J. K. and M. J. Steindler. 1983. "Alteration of Nuclear Waste Glass by Hydration." In Scientific Basis for Nuclear Waste Management VI, ed. D.G. Brookins, North-Holland, New York.

Chick, L. A., R. O. Lokken, D. M. Strachan, and W.M. Bowen. 1986. "Development of a West Valley Nuclear Waste Glass by Empirical Modeling." Bulletin of the American Ceramic Society, 65(2):114-118.

Ebert, W. L., A. J. Bakel, and N. R. Brown. 1996. "Measurement of the Glass Dissolution Rate in the Presence of Alteration Phases," Proceedings of the International Topical Meeting on Nuclear and Hazardous Waste Management, Spectrum '96, Seattle, Washington, August 18-23, 1996, pp. 569-575.

Gong W. L., R. C. Ewing, L. M. Wang, E: Vernaz, J. K. Bates, and W. L. Ebert. 1998. "Surface Layer Formation of the French SON 68 Nuclear Waste Glass During Vapor Phase Alteration at $200^{\circ} \mathrm{C}$," J. Nuclear Materials, 254, 249-265.

Hrma, P., G. F. Piepel, M. J. Schweiger, and D. E. Smith. 1992. First-Order Model for Durability of Hanford Waste Glasses as a Function of Composition. In High-Level Radioactive Waste Management, American Nuclear Society, La Grange Park, Illinois. 
Mann, F. M., R. P. Puigh II, C. R. Eiholzer, Y. Chen, N. W. Kline, A. H. Lu, B. P. McGrail, and P. D. Rittmann. 1998. Hanford Immobilized Low-Activity Tank Waste Performance Assessment. DOE/RL-97-69, Rev. B, Project Hanford Management Contractor, Richland, Washington.

McGrail, B. P and D. K. Peeler. 1995. "Evaluation of the Single-Pass Flow-Through Test to Support a Low-Activity Waste Specification," PNL-10746, Pacific Northwest Laboratory, Richland, Washington.

McGrail, B. P., P. F. Martin, and C. W. Lindenmeier. 1997. Accelerated Testing of Waste Forms Using a Novel Pressurized Unsaturated Flow (PUF) Method. In Scientific Basis for Nuclear Waste Management $X X$, W. J. Gray and I. R. Triay, editors, Materials Research Society, Pittsburgh, Pennsylvania.

McGrail, B. P., W. L. Ebert, D. H. Bacon, and D. M. Strachan. 1998. "A Strategy to Conduct an Analysis of the Long-Term Performance of Low-Activity Waste Glass in a Shallow Subsurface Disposal System at Hanford," PNNL-1 1834, Pacific Northwest Laboratory, Richland, Washington.

Strachan, D. M. and T. L. Croak. 1998. The dependence of Long-Term Dissolution on Glass Composition, Proceedings of the Eighth International Conference on High-Level Radioactive Waste Management, May 11-14, 1998, Las Vegas, Nevada, American Nuclear Society, La Grange Park, Illinois.

Strachan, D. M., W. L. Bourcier, and B. P. McGrail. 1993. "Toward a Consistent Model for Glass Dissolution," Radioactive Waste Management and Environmental Restoration, 19(1-3):129-145. 


\section{Distribution}

No. of

Copies

\section{OFFSITE}

W. L. Ebert

Argonne National Laboratory

Building 205

9700 South Cass Avenue

Argonne, IL 60439-4837

Professor B. Grambow

Ecole de Mines de Nantes

Laboratoire SUBATECH

4 Rue Alfred Kastler

F 44307 Nantes Cedex 3

FRANCE

Dr. P. Dove

Georgia Institute of Technology

School of Earth and Atmospheric Sciences

Atlanta, GA 30332-0340

Dr. P. Van Iseghem

SCK-CEN

Boeretang 20

B-2400 Mol

BELGIUM

Professor M. Weinberg

University of Arizona

1717 E Speedway Blvd

Tucson, AZ 85719-4514

2 University of Florida

College of Engineering

Gainsville, FL 32611

ATTN: Professor D. Clark

Professor J. Simmons
No. of

Copies

4 Westinghouse Savannah River Company

P.O. Box 616

Aiken, SC 29802

ATTN: E. W. Holtzscheiter

C. M. Jantzen

D. K. Peeler

G. W. Wicks

ONSITE

4 U.S. Department of Energy

Richland Operations Office

N. R. Brown

A0-21

Public Reading Room

$\mathrm{H} 2-53$

RL Docket File (2)

H5-36

23 Pacific Northwest National Laboratory

P. Hrma

K6-24

L. Kovach

A0-21

B. P. McGrail

K6-81

G. L. Smith

K6-24

D. M. Strachan (10)

K6-24

J. D. Vienna

K6-24

J. H. Westsik

K9-91

Information Release Office (7)

Distr.1 